\title{
Ultrasound preferred as the immediate preoperative investigation before three-pin rigid fixation: authors' reply
}

\author{
Juan F. Martínez-Lage
}

Received: 27 June 2011 / Accepted: 28 June 2011 /Published online: 9 July 2011

(C) Springer-Verlag 2011

\section{Dear Sir,}

We very much appreciate the interest paid to our paper "Depressed skull fracture by a three-pin head holder: a case illustration" published in Child's Nervous System [1] and the thoughtful comments on our article brought about by Drs. Cowie and Strachan [2]. In our work, we referred to the suggestions made by Wong and Hines concerning the variability of skull thickness in children of different ages at the time of assessing the safest cranial zones to apply the pins of halo devices [3]. The pins of skull tongs, halo devices, and rigid head holders may cause diverse complications related to skull penetration. Some of these hazards include the formation of severe lesions as epidural hematomas and intracranial abscesses. The aim of our paper was to warn about some of these complications that may arise following the use of these pins and to provide alternate methods of head immobilization during neurosurgical procedures. Perhaps, the main recommendation we made was to avoid using these pin-type head holders as much as possible.

In our hospital, children evaluated with the suspicion of harboring a brain tumor at the emergency department are almost always studied by a computerized tomography (CT) head scan as a preliminary screening tool. A head magnetic resonance (MR) is performed later, once the child has been admitted to the ward. In the reported case, the child was admitted with a MR that has been ordered by her pediatrician. In this manner, we had no imaging study that would give us information about the patient's skull thickness. The length of the presurgical evolution and the presence of hydrocephalus on MR should have suggested to

\section{J. F. Martínez-Lage $(\bowtie)$}

Regional Service of Neurosurgery,

Virgen de la Arrixaca University Hospital,

30120 El Palmar, Murcia, Spain

e-mail: juanf.martinezlage@cablemurcia.com us the possibility of a slow-growing tumor and the possibility of associated skull fragility.

In our paper, we suggested to evaluate the state of the skull sutures by palpation. The cranial sutures can be satisfactorily identified by palpation and by well-known anatomical landmarks. Perhaps we should have added to the suggestion of performing a CT scan in children with brain tumors the words "in doubtful or selected cases" to avoid the generalization of this recommendation.

We recognize the hazards associated with the use of CT especially those regarding radiation exposure and the possibility of radiation-induced neoplasms among them. We always try to avoid performing a CT head scan, especially in children with open fontanels that arrive in hospital with the suspicion of hydrocephalus shunt malfunction. However, we still obtain CT scans in cases of a head injury and in patients investigated for craniosynostosis. In the first case, a CT scan is performed due to its immediacy and in the case of the craniosynostosis because we do not rely on ultrasonography alone for evaluating the patency of the skull sutures. In instances with brain tumors, as Drs. Cowie and Strachan suggest, the cranial sutures can be satisfactorily evaluated by ultrasonography, but this method will hardly give information about skull thickness especially in the group of older children.

\section{References}

1. Martínez-Lage JF, Almagro MJ, Serrano C, Mena L (2011) Depressed skull fracture by a three-pin head holder: a case illustration. Childs Nerv Syst 27:163-165. doi:10.1007/s00381-010-1213-z

2. Cowie C, Strachan R (2011) Ultrasound preferred as the immediate preoperative investigation before three-pin rigid fixation. Child's Nerv Syst (in press)

3. Wong WB, Haynes RJ (1994) Osteology pediatric skull. Considerations of halo pin placement. Spine 19:1451-1454 